\title{
El usuario, pieza clave para la creación de una comunidad digital en museos y otras instituciones culturales
}

\author{
Georgina Marcelino Mercedes | Brandversity. CMI Business School \\ URL de la contribución <www.iaph.es/revistaph/index.php/revistaph/article/view/4803>
}

Las redes sociales son las grandes artífices de la revolución de la comunicación en la era digital, han influido en nuestras relaciones personales, en los movimientos sociales y políticos $\mathrm{y}$, por supuesto, en los hábitos de consumo.

Con la llegada de las redes sociales y su posterior inclusión como canal para la comunicación de marcas, empresas e instituciones, los consumidores pasaron de ser exclusivamente clientes a ser también fans o seguidores y de allí a convertirse, además, en prescriptores. El consumidor se transformó de simple receptor a una voz protagonista de una nueva dinámica en la comunicación comercial e institucional.

Hace poco más de una década, el informe Digital World, Digital Life (TNS 2008) indicaba un crecimiento de la confianza de los consumidores en los medios sociales a la hora de tomar decisiones de compra: valorando las opiniones de familiares y amigos, las opiniones de expertos y también las experiencias de otros usuarios a los cuales contactan mediante las redes sociales, no necesitando para ello tener establecida una relación social fuera del entorno digital.

Las redes sociales propician un acercamiento amable a un consumidor cada vez más activo. Esto se extrapola también a las instituciones culturales. Por su propia naturaleza, las redes sociales motivan a las instituciones culturales a crear contenidos más creativos y mejor segmentados para sus canales de comunicación, un paso importante para la constitución de comunidades en torno a la institución y su oferta cultural.

La función más tradicional de los museos, por ejemplo, es la de educar a los públicos y las estrategias de comunicación que se generen para promocionarlos han de convertirse en un vehículo para el logro de dicho objetivo, ¿por qué no usar las redes sociales para que esos primeros contactos sean también educativos? Instituciones museísticas como el Museo Nacional del Prado o el Centro de Arte Reina Sofía ya lo están haciendo.

Otra gran ventaja es la posibilidad de construir los programas y actividades de las instituciones junto a las audiencias, mano a mano, en vez de "para ellos", pudiendo a partir de aquí construir un entorno cultural más inspirador, humano y en consonancia con las necesidades actuales de educación y divulgación.

Las industrias culturales deben hacer frente a un público cada vez más tecnológico, por tanto, han de someterse a los cambios pertinentes con miras a hacer la experiencia de la visita más interactiva permitiendo el acceso digital a sus recursos en los momentos previos y posteriores a la misma. A día de hoy, la definición de usuario de instituciones culturales no se suscribe únicamente al momento de la visita, pues, precisamente a través de las redes sociales y del contacto con una comunidad digital el usuario estará consumiendo contenidos artísticos y/o educativos constantemente, y si los considera de interés los compartirá con sus contactos en diversas plataformas.

Aprovechar el movimiento natural de los usuarios y su predisposición a compartir contenidos en el espacio digital también representa una forma de captar a audiencias cada vez más jóvenes. La llamada Generación Z (nacidos entre 1994 y 2010) no sería probablemente parte de la comunidad digital de algunas instituciones si estas no hubiesen integrado modelos de comunicación digital 
e interactivos en sus correspondientes estrategias. La mayoría de los jóvenes y adolescentes no suele asistir a los museos, a no ser que sea una actividad planteada por un centro educativo; sin embargo, reconocemos que esta audiencia, la joven, es también la que participa más activamente cuando se les dispone de medios adecuados a sus exigencias; la gran mayoría de las cuales se asocian a la interacción y al consumo de contenidos audiovisuales. Según datos investigados por el Pew Research Center, YouTube, Instagram y Snapchat son las redes sociales preferidas por la Generación Z (Parker y Igielnik 2020).

De entre todas las opciones que ofrecen las redes sociales a las instituciones culturales la posibilidad de construir y gestionar comunidades digitales es una de las más aventajadas. Una nueva generación de personas se está formando en escuelas y universidades utilizando las nuevas tecnologías en todos sus procesos de aprendizaje. La importancia de estos procesos y su implementación se puso de manifiesto durante el aislamiento que se hizo efectivo al inicio de la crisis sanitaria asociada a la COVID-19.

Según datos de la UNESCO (2020) la situación generada por el auge de la pandemia COVID-19 cerró el 90 por ciento de los museos a nivel mundial. Recordemos, además, que estos cierres se han producido sin un tiempo de aviso previo que permitiese la adecuación de todos los servicios y la oferta de estas instituciones al entorno digital.

La situación derivada del aislamiento social ha puesto en evidencia la necesidad de mantener una conexión fresca y constante con las audiencias a través de los medios digitales.

En esta misma línea se ha demostrado la importancia de hacer de las redes sociales parte natural de los procesos de comunicación de las instituciones, pues la que ya rcontaban con perfiles relevantes y redes fortalecidas pudieron empezar a funcionar vía digital casi inmediatamente.
De acuerdo lo publicado en el portal web del ICOM (Simón Diez 2020), hay dos tendencias sobresalientes de cara a la creación de comunidades culturales digitales en la actualidad: la importancia de reforzar la comunidad digital partiendo de un conocimiento profundo del perfil de los usuarios que conforman dichas comunidades, adaptando el contenido de los canales digitales a sus intereses y el uso de nuevas formas de expresión que involucren a la Generación Z, accediendo a plataformas de redes sociales con carácter principalmente audiovisual en las que dicha generación participa activamente como YouTube, TikTok, Instagram o Snapchat.

La creación de comunidades digitales en museos y otras instituciones culturales es una posibilidad real, de hecho ya están aquí, y su creación y mantenimiento dependerán en gran medida de que la personalización de la comunicación con los usuarios sea el centro de las estrategias de comunicación que se pongan en marcha.

\section{BIBLIOGRAFÍA}

- Parker, K. y Igielnik, R. (2020) On the Cusp of Adulthood and Facing an Uncertain Future: What We Know About Gen Z So Far. Pew Research Center, Social \& Demographic Trends, 14 de mayo de 2020. Disponible en: https://www. pewsocialtrends.org/essay/on-the-cusp-of-adulthood-andfacing-an-uncertain-future-what-we-know-about-gen-z-so-far/ [Consulta: 03/12/2020]

- Simón Diez, A. (2020) Entre lo personal y lo viral: la reinvención de la comunicación del museo. ICOM, 21 de septiembre de 2020. Disponible en: https://icom. museum/es/news/reinvencioncomunicacion-del-museo/ [Consulta: 03/12/2020]

- TNS (2008) Digital world, digital life: Snapshots of our online behavior and perspectives around the world. Disponible en: http://uploadi.www.ris.org/editor/1233258932TNS_Market Research_Digital_World_Digital_Life.pdf [Consulta: 15/12/2020]

- UNESCO (2020) Covid-19 crisis closes 90 percent of museums globally, UNESCO plans for reopenings. UN news, 18 de mayo de 2020. Disponible en: https://news.un.org/en/ story/2020/05/1064362 [Consulta: 03/12/2020] 